\title{
Does theophylline really improve acute mountain sickness?
}

\section{From the authors:}

RöGGLA et al. [1] performed a double-blind, placebocontrolled crossover trial in eight subjects to investigate the effects of "nonretardized" theophylline on oxygen tension in arterial blood $\left(\mathrm{Pa}, \mathrm{O}_{2}\right)$ and carbon dioxide tension in arterial blood $\left(\mathrm{Pa}_{\mathrm{a}} \mathrm{CO}_{2}\right), 2 \mathrm{~h}$ after ingestion of $300 \mathrm{mg}$ theophylline. They did not demonstrate a significant increase of $\mathrm{Pa}_{2} \mathrm{O}_{2}$ or significant decrease of $\mathrm{Pa}_{\mathrm{a}} \mathrm{CO}_{2}$ in the theophylline group and questioned the evidence of our study indicating a positive effect of theophylline on acute mountain sickness (AMS). However, there were major differences between both studies. First, RöGGLA et al. [1] studied eight healthy volunteers at moderate altitude $(2600 \mathrm{~m})$ compared to 21 volunteers at $3500 \mathrm{~m}$ in our study, therefore decreasing substantially the incidence of AMS. It seems questionable how the authors want to evaluate an effect of theophylline on AMS, when they did not measure symptoms of AMS. Furthermore, ventilatory adaptation was measured only indirectly by means of change of blood gases without any other cardiopulmonary parameters (respiratory frequency, pulse rate). Serum levels of theophylline in the verum group have not been reported, so it remains unclear whether the subjects reached therapeutic serum levels during blood gas analysis. Due to the oral slow-release theophylline we used, the time points chosen for measurements were not comparable and late effects (after $18 \mathrm{~h}$ in our investigation) were missed in the study of RöGGLA et al. [1].

In our study [2], mean serum theophylline serum levels were $40.5 \mu \mathrm{M}$ in the decompression chamber study and $51.4 \mu \mathrm{M}$ in the high-altitude study, respectively. In both parts of our study, oxygenation was improved in the verum group. However, the increase in $P a, O_{2}$ or arterial oxygen saturation and the decrease in $P a, C_{2}$ was not always significant, as in the study of RöGGLA et al. [1]. In contrast to the known small ventilatory stimulating effects of theophylline, we found a significant effect of theophylline on AMS, compared to placebo. However, we found no correlation between oxygenation and severity of AMS. This is in accordance to the observation that hypoxic ventilatory response and AMS are not correlated [3].

This discrepancy between the small increase in oxygenation, but definite improvement of symptoms of AMS might be explained by different modes of action of theophylline at high-altitude (phosphodiesterase inhibition, increase of central respiratory drive, reduction of cerebral blood flow, prevention of leakage of cerebral vascular endothelium, etc.).

Since RöGGLA et al. [1] did not study any of these mechanisms it seems speculative to derive any far reaching conclusions concerning the effect of theophylline from their limited data. We do not feel that our data are really contradicted by their work. However, we agree with them that the issue of improvement of acute mountain sickness by theophylline is of high interest and further investigations are needed to elucidate the effects of theophylline at high-altitude.

\section{R. Fischer, S.M. Lang, R.M. Huber}

Pneumology, Medizinische Klinik Innenstadt, University of Munich, , Ziemssenstrasse 1, 80336 München, Germany.

\section{References}

1. Röggla G, Domej W, Röggla M. Does theophylline really improve acute mountain sickness? Eur Respir $J$ 2001; 17: 575.

2. Fischer R, Lang SM, Steiner U, et al. Theophylline improves acute mountain sickness. Eur Respir J 2000; 15: $123-127$.

3. Milledge JS, Thomas PS, Beeley JM, et al. Hypoxic ventilatory response and acute mountain sickness. Eur Respir J 1988; 1: 948 -951. 